IZA DP No. 5408

Disability and Multi-State Labour Force Choices with State Dependence

Umut Oguzoglu

December 2010 


\title{
Disability and Multi-State Labour Force Choices with State Dependence
}

\author{
Umut Oguzoglu \\ University of Manitoba \\ and IZA
}

\section{Discussion Paper No. 5408 \\ December 2010}

\author{
IZA \\ P.O. Box 7240 \\ 53072 Bonn \\ Germany \\ Phone: +49-228-3894-0 \\ Fax: +49-228-3894-180 \\ E-mail: iza@iza.org
}

Any opinions expressed here are those of the author(s) and not those of IZA. Research published in this series may include views on policy, but the institute itself takes no institutional policy positions.

The Institute for the Study of Labor (IZA) in Bonn is a local and virtual international research center and a place of communication between science, politics and business. IZA is an independent nonprofit organization supported by Deutsche Post Foundation. The center is associated with the University of Bonn and offers a stimulating research environment through its international network, workshops and conferences, data service, project support, research visits and doctoral program. IZA engages in (i) original and internationally competitive research in all fields of labor economics, (ii) development of policy concepts, and (iii) dissemination of research results and concepts to the interested public.

IZA Discussion Papers often represent preliminary work and are circulated to encourage discussion. Citation of such a paper should account for its provisional character. A revised version may be available directly from the author. 
IZA Discussion Paper No. 5408

December 2010

\section{ABSTRACT}

\section{Disability and Multi-State Labour Force Choices with State Dependence*}

I use a dynamic mixed multinomial logit model with unobserved heterogeneity to study the impact of work limiting disabilities on disaggregated labour choices. The first seven waves of the Household Income and Labour Dynamics in Australia survey are used to investigate this relationship. Findings point out to strong state dependence in employment choices. Further, the impact of disability on employment outcomes is highly significant. Model simulations suggest that high cross and own state dependence can amplify a one-off disability shock to alter the probability of full time employment and nonparticipation permanently, especially for low skilled individuals.

JEL Classification: J14, J21,C23

Keywords: disability, employment, dynamic mixed multinomial logit, panel data, HILDA, simulated maximum likelihood

Corresponding author:

Umut Oguzoglu

University of Manitoba

Department of Economics

647 Fletcher Argue Bld.

Winnipeg MB

Canada

E-mail: oguzoglu@cc.umanitoba.ca

\footnotetext{
* This paper uses the confidentialised unit record file (release 7) of the Household, Income and Labour Dynamics in Australia (HILDA) survey. The HILDA Survey project was initiated and is funded by the Australian Department of Family and Community Services (FaCS) and is managed by the Melbourne Institute of Applied Economic and Social Research. The findings and views reported in this paper, however, are those of the author and should not be attributed to either FaCS or the Melbourne Institute. Author would like to thank to Julia Witt and Victoria Prowse for valuable comments.
} 


\section{INTRODUCTION}

Ill health is strongly associated with being out of work and being out of the labour force (Bound, 1991; Cai, 2010; Campolieti, 2002; Stern, 1989). This adverse effect persists even after controlling for unobserved individual heterogeneity and state dependence that drive employment behaviour (Gannon, 2005; Kapteyn, Smith, \& van Soest, 2008; Oguzoglu, 2010). Yet, non-work (or non-participation) is only one of the available options facing disabled people.

In a broader sense, alternative employment such as a part time employment is a common response to job loss (Farber, 1999). There is also evidence that full time working men switch to part-time work, or to non-work, in response to health shocks (Riphahn 1999). However, in the absence of statutory laws that guarantee their full-time work back, the intertemporal effect of such a switch on future employment outcomes may be ambiguous. Although part-time employment is an undeniably useful channel to enter (or re-enter) employment, it hardly guarantees future full-time employment (Blank, 1989). Therefore, if part-time employment is not a sufficient stepping stone to full-time employment, the full effect of a disability shock that forces an individual to leave full-time work may outlast the effect that it has on an individual's health. Unemployment scarring (Arulampalam et al. 2001, Ruhm 2010) may have similar adverse effect for those who transit into unemployment due to disability shocks. This may be due to erosion of firm-specific human capital during unemployment spells, and to employers taking the episode of non-work as a signal of low productivity.

Within the aforementioned context, this paper's aim is twofold. The first aim is to capture whether or not a work limiting disability significantly influences individual decisions to leave or stay in an employment state. This is similar to the transitions investigated by Riphahn (1999); however, I do not restrict the sample to older men in full-time employment but analyse working 
age men and women who are in one of the following employment states: full-time employed, part-time employed, unemployed, not in the labour force. The second aim of this paper is to demonstrate that, due to persistent nature of employment behaviour, the full effect of a disability shock may be much more severe than its initial impact on current employment outcomes. Charles (2003) and Mok et al. (2010) show that a work disability has long lasting effect on earnings. They argue that long recovery periods may be due to loss of accumulated human capital. My findings are consistent with this view in that both the intertemporal and immediate impact of a disability shock depend on the skill levels and employment histories of individuals.

I estimate several dynamic multinomial models to examine the impact of work limiting disabilities on the employment decisions of Australian working age men and women separately. Australia is an ideal candidate to analyse multi-state employment dynamics of disability because it has the third highest rate of part-time employment among OECD countries (OECD, 2010). With an aging population and increasing prevalence of disability, it mirrors problems that other industrialised nations face.

The econometric methodology closely follows Gong et al. (2004) and Prowse (2010) where dynamic mixed multinomial logit models with random effects are estimated via simulated maximum likelihood method. The models allow for state dependence, endogenous initial conditions and unobserved individual specific heterogeneity in the form of random effects. The utility maximizing choice, given observed and unobserved characteristics, employment and health history, is assumed to be the observed employment state. Exogenous disability and random effect assumptions are relaxed by estimating dynamic linear probability models with fixed effects. 
The rest of the paper is organised as follows. Section 2 introduces the dataset and reports statistics describing the dynamics of disability reporting and employment behaviour. Section 3 presents the multivariate model and section 4 discusses the result and presents model simulations, section 5 concludes.

\section{DATA AND SAMPLE}

The data used for this paper come from the first seven waves of the Household, Income and Labour Dynamics in Australia (HILDA) Survey. Details of this survey are documented in Watson \& Wooden (2004). In 2001, 7,683 households representing 66 percent of all in-scope households were interviewed for the first wave of HILDA, generating a sample of 15127 persons who were at least 15 years old and eligible for interviews, of whom 13969 were successfully interviewed. Subsequent interviews for later waves were conducted one year apart. The HILDA survey contains detailed information on each respondent's labour market history, sociodemographic characteristics and various self-reported health measures. The multi-state labour force status used in this paper is obtained from the detailed employment state variable in which respondents are recoded as one of following: full time employed, part time employed, unemployed and out of labour force ${ }^{1}$. The part time work status is based on the Australian Bureau of Statistics' definition of part time work which is less than 35 hours of work per week. The work limitation status used in this paper comes from following survey question:

“[...] do you have any long-term health condition, impairment or disability that restricts you in your everyday activities, and has lasted or is likely to last, for 6 months or more?"

\footnotetext{
${ }^{1}$ In fact the raw employment status variable breaks down unemployed category further into a marginally attached and a marginally unattached. I combined these categories into a single unemployed category.
} 
While this question is asked, specific examples of long-term health conditions were shown on a card. These include, among many others, limited use of fingers or arms, and problems with eyesight that could not be corrected with glasses or contact lenses. Studies by Nagi (1969), Maddox \& Douglas (1973) and LaRue et al. (1979) find close correlation between self-reported health status such as the one used in this paper and medically determined health status. Oguzoglu (2010) shows that the self-reported work limitation in HILDA is highly correlated with detailed health information such as hospital admissions, SF-36 Physical functioning index (Ware, 2000) and prevalence of specific health conditions (arthritis, cancer...etc). Similar results are reported by Riphahn (1999) using health satisfaction from the German Socio-economic Panel (GSOEP) and by Burkhauser \& Daly (1994) using self-reported disability status from GSOEP and from the Panel Study of Income Dynamics (PSID).

\subsection{Characteristics of the Sample}

The sample contains an unbalanced sample of persons aged 24 to 65 years. People in fulltime study, individuals who receive old age pension and anyone with missing observations or who are observed less than two consecutive periods are removed from the sample. The final sample consists of 25,984 observations from 1,787 men and 1,925 women. Table 1 describes demographic characteristics of the sample.

\subsection{Dynamics Association of Disability and Work}

In this section, I present statistics describing the dynamic relationship between work disability and employment choices. The proportions of observed employment states are summarised for each gender and disability category in Table 2. Work limitation is associated with a higher likelihood of being out of the labour force (nonparticipation), unemployment and

part-time work for men. Compared to 84 percent of not disabled men, only 34 percent of 
disabled men are working in full-time jobs. 48 percent of disabled men are out of the labour force with compared to 6 percent of not-disabled men. Part-time employment is more prevalent among disabled (13 percent) than not disabled men ( 8 percent). For women, work disability is associated with lower full time and part time employment and higher unemployment and labour force non-participation.

In Figure 1 and Figure 2, the association of work disability and employment choices are presented over time. The four separate panels of Figure 1 present the percentage of individuals that transit into full time employment conditional on their employment status at $t=1$. Two groups of men and women are examined. The first group are individuals who report a work limitation in wave 1 (the disabled group). The second group consists of persons who never report a disability (the not-disabled group). For men, the probability of continuing full-time employment declines more sharply for the disabled group than does it for the not-disabled group. Transition into full-time employment remains constant over time for disabled persons who were initially out of the labour force, and the likelihood start increasing only at $t=3$ for individuals who were initially employed part-time or unemployed. On the other hand, for the not-disabled persons who belong to these initial labour force categories the likelihood of full time work is increasing over time.

Another notable difference between disabled and not-disabled group is how unemployed fair against the part-time workers. Not-disabled unemployed has significantly higher likelihood than part-time workers to transit into full-time employment. For the disabled group, however, the unemployed and part-time employed are equally likely to be in full time employment. For women, apart from a sharper decline in the probability of continuing on full time work for the disabled group, no significant difference is observed across the disabled and not disabled group. 
Figure 2 reports transition rates into part time work conditional on initial employment states and disability. The probability of staying in part time employment declines for both groups, however, the decline is steeper for disabled persons. Transition rates are relatively constant for all employment states for the disabled group, while for the not-disabled group, the rates are increasing for the unemployed, nonparticipants and (to some degree) for full-time workers.

Statistics presented in this section imply a highly dynamic interaction between employment and disability. Disabled are less likely to find employment or to stay employed than not-disabled. Given the demographic differences between people with and without a disability, this does not imply a casual effect of disability. Observed patterns may be due differences in human capital or other unobserved factors that lower labour force attachment for the disabled. Therefore, a more accurate measure of the disability effect on employment choices requires multivariate modelling. The dynamic multivariate model presented in the next section aims to capture this complex relationship.

\section{METHODOLOGY}

An individual's labour supply problem can be written as follows ${ }^{2}$ :

$$
\operatorname{Max}_{j} U_{j}\left(\alpha_{i, j}, X_{i, t}, D_{i, t}, \Omega_{i, t-1}, \epsilon_{i, j, t}\right)
$$

where $U_{j}\left(\alpha_{i, j}, X_{i, t}, D_{i, t}, \Omega_{i, t-1}, \epsilon_{i, j, t}\right)$ refers to individual $i$ 's utility if she chooses employment alternative $j$ at time $t . X_{i, t}$ is a vector of individual characteristics and $D_{i, t}$ is an individual's health history up to an including time $t . \alpha_{i j}$ are individual and choice specific factors that are time invariant and unknown to the researcher. $\Omega_{t-1}$ represents an individual's employment history up to $t-1$. I assume that each individual can be in any one of following

\footnotetext{
${ }^{2}$ The notation in this section is largely adapted from Prowse 2010 and Gong et al 2004.
} 
employment states: full time work $(j=F T)$, part time work $(j=P T)$, unemployment $(j=U N E)$ and not in the labour force $(j=N I L F)$. The utility maximizing employment state is assumed to be the observed state.

For the empirical implementation of the maximization problem I specify a linear approximation to the value of choosing employment state $j$ at time $t$ as follows:

$U_{j}\left(\alpha_{i, j}, X_{i, t}, D_{i, t}, \Omega_{i, t-1}, \epsilon_{i, j, t}\right)=\gamma_{j} y_{i, j, t-1}+\delta_{1, j} D_{i, t}+\delta_{2, j} D_{i, t-1}+\beta_{1} X_{i, t}+\alpha_{i, j}+\epsilon_{i, j, t}$

In (2), $y_{i, j, t-1}$ is $3 \times 1$ vector of lagged employment state indicators (with NILF $_{\mathrm{t}-1}$ being the reference category, available lagged state dummy variables are $\left.\mathrm{FT}_{\mathrm{t}-1}, \mathrm{PT}_{\mathrm{t}-1}, \mathrm{UNE}_{\mathrm{t}-1}\right) . X_{i, t}$ includes age, age squared, education, broad occupational categories, employment and unemployment history, county of birth, marital status, an indicator for dependent children in the household, interaction of marital status and dependent children, logarithm of non-labour income, partner's labour force status and time dummies. $D_{i, t}$ and $D_{i, t-1}$ are dichotomous variables that capture current and lagged work limitation statuses. The random disturbance term $\epsilon_{i, j, t}$ is assumed to be independent from everything else in the model and follow a Type I extreme value distribution. Hence, the probability of making choice $j$ at $t>1$ conditional on $X_{i t}, y_{i, j, t-1}$ and $\alpha_{i j}$ takes the following logit form:

$$
P\left(j \mid X_{i t}, \alpha_{i}\right)=\frac{\exp \left(y_{i, t-1, j} \gamma_{j}+X_{i t} \beta_{j}+\delta_{1 j} D_{i, t}+\delta_{2 j} D_{i, t-1}+\alpha_{i j}\right)}{\sum_{k=1}^{J} \exp \left(y_{i, t-1, k} \gamma_{k}+X_{i t} \beta_{k}+\delta_{1} D_{i, t}+\delta_{2 k} D_{i, t-1}+\alpha_{i k}\right)}
$$

The person specific unobserved factors are modelled as random effects by assuming that $\alpha_{i}=\left(\alpha_{2}, \alpha_{3}, \alpha_{4}\right)^{\prime}$ come from a trivariate normal distribution.

Due to its ability to combine mixtures of distributions, the above model is often referred to as the mixed multinomial logit (MMNL) model (Train, 2009). One caveat with the random effect assumption is that unobserved heterogeneity should be assumed to be uncorrelated with 
the observed characteristics of the model. In order to relax this assumption time averages of all time varying variables in $X_{i t}$ are added to the model as in Mundlak (1978).

Another important issue is the initial conditions problem (Heckman, 1981). The problem is that initial realisations of employment, which are unobserved for the majority of individuals in the data, have a crucial impact on entire path of employment outcomes. Treating initial conditions as exogenous produces inconsistent estimates. I follow Gong et al (2004) and Prowse (2010) to approximate the initial conditions with a static multinomial logit model using data from the first observed period ${ }^{3}$. This initial conditions equation is estimated jointly with the dynamic model. The linear approximation of utility of chosen state $j$ at time $t=1$ can be written as:

$$
U(i, j, 1)=x_{i, 1}^{\prime} \pi_{j}+\theta_{i, j}+\epsilon_{i, j, 1}
$$

where $x_{i, 1}$ contains information available from the first period including the disability status. The probability of individual $i$ being in labour state $j$ at time $t=1$ is:

$$
P\left(j \mid x_{i 1}, \theta_{j i}\right)=\frac{\exp \left(x_{i 1}^{\prime} \pi_{j}+\theta_{i j}\right)}{\sum_{k=1}^{J} \exp \left(x_{i 1}^{\prime} \pi_{j}+\theta_{i j}\right)}
$$

The $\theta_{i}=\left(\theta_{2}, \theta_{3}, \theta_{4}\right)^{\prime}$ is assumed to be generated from the random effects in (1) and satisfy the following:

$$
\theta_{i}=C \alpha_{i}=B \eta_{i} ; \eta_{i} \sim N\left(0, I_{3}\right)
$$

where $\mathbf{B}$ is $3 \times 3$ correlation matrix to be estimated. The individual contribution to the likelihood for the MMNL model has the following form:

$$
L_{i}(\eta)=\prod_{j=1}^{J} P\left(j \mid x_{i, 1}, \theta_{i j}\right) \prod_{t=2}^{T} \prod_{j=1}^{J} P\left(j \mid x_{i, t}, D_{i, t}, D_{i, t-1} y_{i, j, t-1}, \alpha_{i, j}\right)
$$

\footnotetext{
${ }^{3}$ This approach is first suggested by Heckman (1981) for the case of dynamic probit models with random effects.
} 
Since the individual effects are unknown, they have to be "integrated out" of the likelihood function. I employ a simulated maximum likelihood method using the recursive simulator ${ }^{4}$. The procedure can be summarised as follows: consider likelihood function for the entire sample:

$$
L=\prod_{i=1}^{N} \int_{-\infty}^{\infty} \int_{-\infty}^{\infty} \int_{-\infty}^{\infty} L_{i}\left(\eta_{i}\right) f\left(\eta_{i}\right) d\left(\eta_{i 2}\right) d\left(\eta_{i 3}\right) d\left(\eta_{i 4}\right)
$$

where $f\left(\eta_{i j}\right)$ is the density of $\eta_{j}$. The first step is to transform pseudo-random draws ${ }^{5}$ to trivariate normal distributed random effects in order to satisfy (6); these random effects are then plugged into the likelihood function. After $\boldsymbol{R}$ repetitions, simulated likelihood values are averaged and the simulated likelihood is iterated until convergence, while for each iteration, new random numbers are drawn. The integral in (8) is thus replaced by

$$
L_{i}^{R}=\frac{1}{R} \sum_{r=1}^{R} L_{i}\left(\eta_{i}^{r}\right)
$$

In the empirical work I use $\mathrm{R}=100^{6}$.

${ }^{4}$ This simulator is also known as the GHK simulator after works by Geweke (1988), Hajivassiliou (1993), and Keane (1994)

${ }^{5}$ I use Halton numbers to generate random effects which are shown to reduce the number of replication considerably (Train 2009). For more details on the estimation method see Gong et al (2004) and Prowse (2010).

${ }^{6}$ There are no significant differences in results when 50 replications are used, when $\mathrm{R}=20$ there were convergence problems. 


\subsection{Linear Probability Models and GMM}

The consistency of the MMNL results rely on the strict exogeneity of work disability and other observed characteristics and normality of the random effects. In order to test the robustness of the results, I estimate several linear probability models with fixed effects. The following three linear binary models (LPM) are estimated separately for full-time work, parttime work and unemployment.

$$
\begin{aligned}
& y_{i, t}^{F T}=\gamma_{1} y_{i, t-1}^{F T}+\beta_{1} Z_{i t}+\beta_{2} D_{i t}+\beta_{3} D_{i, t-1}+\eta_{i}^{F T}+\epsilon_{i t}^{F T} \\
& y_{i, t}^{P T}=\gamma_{2} y_{i, t-1}^{P T}+\beta_{4} Z_{i t}+\beta_{5} D_{i t}+\beta_{6} D_{i, t-1}+\eta_{i}^{P T}+\epsilon_{i t}^{P T} \\
& y_{i, t}^{U E}=\gamma_{3} y_{i, t-1}^{U E}+\beta_{7} Z_{i t}+\beta_{8} D_{i t}+\beta_{9} D_{i, t-1}+\eta_{i}^{U E}+\epsilon_{i t}^{U E}
\end{aligned}
$$

Where $Z_{i t}$ is the time varying variables in $X_{i t}$. The models are estimated individually by System GMM Arellano \& Bover (1995). In this approach, the models in (10) and their firstdifferenced counterparts are estimated together in a stacked form ${ }^{7}$. The unobserved heterogeneity is removed by simply first-differencing the models, which allows one to be agnostic about $\operatorname{Corr}\left(\eta_{i}, Z_{i t}\right)$, which is assumed to be zero for the MMNL model, and about the distribution of $\eta_{i}$. More importantly, LPM allows endogeneity of work limitation in two forms: one that is due to unobserved time invariant heterogeneity that may jointly drive employment and disability reporting ${ }^{8}$ and another that is due to time varying unobserved factors. The first source is eliminated by removing the fixed effects. The second source of endogeneity is controlled for by

\footnotetext{
${ }^{7}$ For example the first difference model for FT state is: $\Delta y_{i t}=\gamma \Delta y_{i, t-1}+\beta \Delta X_{i t}+\Delta \epsilon_{i t}$ where $\Delta$ is the first difference operator.

${ }^{8}$ This is the type of endogeneity that is controlled for in Kapteyn et al (2008) and Oguzoglu (2010) using multiple equation models that are linked via random effects that come from same multivariate distribution.
} 
appropriately adjusting the moment conditions that the GMM estimator is based on. For example, if disturbances in all three binary models satisfy $E\left(\epsilon_{i t}, \epsilon_{i, t-2}\right)=0$, then $y_{i j t-2}$ and earlier lags are valid instruments for the first differenced model. Moreover, with strictly exogenous individual characteristics, all $Z_{i, t}$ and earlier lags are also valid instruments. If individual characteristics are endogeneous, only $Z_{i, t-2}$ and earlier lags are valid instruments. For empirical implementation of the models, I assume that the current work limitation and lagged employment states are endogenous. All other characteristics are assumed to be strictly exogenous. The validity of instruments is tested using the Sargan test of over-identification. Further, since the instruments are valid only if errors do not follow an $\operatorname{AR}(2)$ process, I tested for second degree serial correlation following Arellano \& Bond (1991). When AR(2) is detected, $y_{i j, t-2}$ are added to (10) and the models are re-estimated.

\section{Results}

In this section, results from the estimation of model (1) are discussed. I provide estimates of two versions of the dynamic MMNL model. The first set of results is obtained by estimating the Dynamic Model as it is described in (2). The second set of estimates comes from the estimation of a Dynamic Interaction Model that includes the interaction of lagged employment and current disability. The interaction model gives a clearer picture of the destination state for people who switch states due to disability. Moreover, we can see whether or not the magnitude of the disability effect depends on the source state. All models are estimated separately for male and female sub-samples. The base category for each model is not in the labour force (NILF). Therefore, a positive estimated coefficient of a given characteristics $X_{k}$ for the outcome $j$ refers to a higher likelihood of choosing employment state $j$ over NILF in the presence of the characteristic $X_{k}$. 
The results for the dynamic multinomial model are reported in Table 3 and Table 4, for men and women, respectively. The impact of statistically significant control variables can be summarised as follows. Education increases the probability of employment over nonparticipation. For women, the probability of full-time and part time employment is increasing in age whereas age is only a minor factor for men. Marriage and dependent children slightly increase the likelihood of full-time work for men. Single men with no dependents are more likely to be nonparticipants and less likely to work part-time. Single women with dependent children and married women without dependent children are less likely to be in the labour force. Having a labour force participant partner raises the likelihood of participation for both samples. Higher non-labour household income is associated with a lower probability of full time employment for women but does not alter employment choices for men.

Focusing on lagged employment state variables, there is a great degree of persistence in all employment outcomes. Compared to a nonparticipant, a current full time worker has a higher likelihood of being in full-time employment in the next period. Similarly, current part time work and unemployment are associated with higher likelihood of future part-time work and future unemployment, respectively. There is also evidence of strong cross-state dependence. Part-time employment and unemployment are associated with a higher probability of future full-time employment compared to current nonparticipation. Unemployment (relative to nonparticipation) also raises the likelihood of full time work in the next period.

The mean of the random effects, $\alpha_{j}$, is estimated significantly. The variance of $\alpha_{j}$ is also significant for all states except unemployment for men, however the magnitude of the random effect is much lower than the impact of the time variant unobservables (normalised to be $\pi^{2} / 6$ ) The correlation of random effects across employment states imply that the unobserved individual 
specific factors that drive each employment choices overlap but are not exactly the same. Except for the likelihood of female unemployment, the adverse impact of a current work limitation is highly significant for all employment states, even after controlling for observed characteristics, unobserved person specific factors and state dependence.

The results from the Dynamic Interaction models are reported in Table 5. I report only the variables of interest to save space. For women, interaction variables for the unemployment state are estimated imprecisely; also, the coefficient of lagged unemployment and current disability interaction is insignificant for the part-time state. However, all other interaction terms are highly significant. The sign of the significant interaction terms suggests that work limitation shocks significantly affect own state dependence. A disabled individual who worked part-time at $t-1$ is less likely to stay in part-time employment and more likely to switch out of labour force at $t$ than a not disabled individual who worked part time at $t-1$. The disability shocks also alter the cross-state dependence. For example, an unemployed person at $t-1$ is more likely to become a nonparticipant and less likely to become full time employed at $t$ if he becomes disabled at $t$, than unemployed person who does not become disabled.

\subsection{Average Partial Effects}

The estimated coefficients of nonlinear probability models do not have a useful interpretation, save for their sign and significance. The average partial effects (APE) for variables of interest are computed for an average man and an average woman, and random effects are assumed to be zero ${ }^{9}$. The APE of a characteristic $k$ represents the percentage increase

${ }^{9}$ See Wooldridge 2004 a detailed discussion on APE for binary models. APE statistics were also computed via simulation using the estimated mean, and covariance matrix of the random effects. The results were not significantly different. 
in probability of observing state $j$ in response to having the characteristic $k$. The results are presented in Table 6.

Full-time employment exhibits the highest persistence over time while unemployment exhibits the lowest. Full-time working men are, on average, 50 percent more likely to be working full time in the next period compared to men who are not currently participating in the labour force. Persistence of full time employment is higher for women, around 65 percent. Part-time work is also highly state dependent: current part-time employment is associated with a higher likelihood of future part-time work by 28 and 41 percent for men and women, respectively. For both men and women, working part time increases the probability of switching to full time work. However, the increase in the probability of full-time work due to past unemployment is much higher. Unemployed men have a 22 percent higher likelihood than nonparticipant men to become a full-time worker in the next period. The increase in the likelihood of full-time employment due to past part-time work is only around 8.5 percent.

A work limitation shock decreases the probability of full-time work by 11.5 and 8.4 percent for men and women, respectively. The probability of nonparticipation is increased by around 8 percent for men and 9 percent for women. The increase in the likelihood of unemployment due to a work disability is around 1 percent for both sub-samples. The likelihood of working part-time decreases by 1.6 percent for women and increases by 2 percent for men. This implies that, on average, disability shocks make employed women switch to nonparticipation and unemployment, whereas full time working men also transit into part time work due to a disability shock. The APEs of the dynamic interaction model support these transition patterns. According to the results, the increase in the likelihood of part-time work for men has two sources: first, a part-time worker at $t-1$ is more likely to continue to work part- 
time if he becomes disabled at $t$ compared to a part time worker that does not become disabled. Second, men from all other employment states are more likely to switch to part-time work and less likely to switch to (or stay in) full-time work if they become disabled at $t$ compared to their counterparts that are not disabled. For women, the small decline in the probability of part time work estimated by the dynamic model masks large heterogeneity across lagged employment states. Women who become disabled at $t$ and were unemployed or full-time employed at $t-1$ are more likely to transit into part-time work (by 3 and 4.8 percent, respectively) than their notdisabled counterparts. On the other hand, disabled women who are employed part time at $t-1$ are far more likely (around 9.3 percent) not to participate in the labour force than part time working women who are not disabled. Another interesting pattern that is implied by the interaction model is that lagged unemployment is associated with the highest disability penalty. Unemployed men and women are 35.7 and 16.7 percent less likely to become full time employed if they are disabled at $t$.

\subsection{Fixed Effect Estimates}

The results from LPM with fixed effects are presented in Table 7 for men and Table 8 for women. Each column of the tables refers to a separate dynamic linear probability model. The coefficients are ready to be interpreted as marginal effects. Note, however, that since LPM does not constraint predicted probabilities to be between 0 and 1, marginal effects may not be directly comparable to the APEs reported earlier. I estimate two lagged specifications for each model. An AR(1) model, which includes only the employment states from the previous period, and an $\mathrm{AR}(2)$ model which includes lag states from $t-1$ and $t-2$. The $\mathrm{AR}(2)$ models are estimated to correct for second degree serial correlation in the errors. All lagged employment states and the current work limitation are assumed to be endogenous. 
The Sargan test confirms the validity of the instruments used in the models. The presence of second degree serial correlation in the full-time employment models for men and women, and in the part-time employment model for women cannot be rejected. Therefore, AR(2) specification for these models are more appropriate. The fixed effects results confirm strong own state dependence implied by the MMNL results. Cross-state dependence for the part-time employment model for men, and the unemployment model for women are estimated imprecisely. However, the sign and significance of the coefficients of all other lagged state variables are consistent with the MMNL results.

Focusing on the work disability variable, after controlling for fixed effects and endogeneity of work disability, work limitation is no longer significant in the probability of unemployment for men and women, and the probability of part-time work for men. Note that although it was estimated significantly by MMNL model, the average partial effect of work disability on unemployment is only around 1 percent. The APE of work limitation on part time work is also small, around 2 percent. The impact of work disability on full time employment is highly significant for both sub-samples. Also, the work disability effect on part time work for women is highly precise. Assuming that predicted probabilities are between 0 and 1 , the magnitude of the disability effect can be interpreted as follows: the probability of full time work declines by 9.5 percent and 11 percent for disabled men and disabled women respectively. The effect of work limitation on part time work is much higher than the APEs of the MMNL model, around 6.6 percent.

\subsection{Intertemporal Effect of Disability}

The Average Partial Effects that are presented in the previous section measures the immediate response of individual employment choices to work limitation shocks. These results 
may mask the true effect of a work disability. For example, if a disabled person switches from full-time to part-time employment but is unable to switch back to full-time employment, the full effect of disability may last multiple periods. I demonstrate this possibility by using model simulations as follows: The effect of a disability shock is simulated by using parameters of the Dynamic Models for high-skilled and low-skilled men and women separately. Low-skilled is defined as persons without a Bachelor degree or higher and work (or previously work) in blue collar professions. High-skilled individuals are defined as those with a Bachelor degree or higher, and work (or preciously work) in managerial or administrative jobs. All other characteristics are set to their gender specific sample averages. The shock is introduced at $t=2$. Individuals are assumed to be not disabled before and after the shock.

The employment response for the high skilled men and women are presented in Figure 3. For men, the probability of full-time employment declines sharply as a response to the disability shock at $t=2$. This decline is mainly due to increases in the probability of non-participation and the probability of part-time employment. Although the likelihood of non-participation returns back to pre-shock levels by $t=4$, the effect of the disability shock on the probability of full-time employment takes until $t=6$ to be fully realised. This is mainly due to the slow decline of the probability of part-time employment following the sharp increase in $t=2$. This implies that individuals who chose to switch to a part-time employment due to a disability shock may have difficulties to return back to full-time employment.

For high-skilled women, the initial increase in the probability of non-participation is higher than high-skilled men's. The probability of part-time employment rises but lower in magnitude than does for high-skilled men. This implies that although there is also transition into part-time work, the majority of high-skilled women switch out of the labour force in response to 
a disability shock. An interesting pattern is that the simulated likelihood of part-time employment increases for periods 4 and 5. This suggests that women who initially left the labour force due to a disability are expected to re-enter employment via part-time work. These two factors prolong the effect of the disability on high-skilled women's full time employment prospects. The likelihood of full-time employment returns back to pre-shock levels only 6 years after the shock.

In Figure 4, I present the intertemporal disability effect on employment choices of lowskilled persons. The initial increase in the likelihood of non-participation for low-skilled men is much higher than that of the high-skilled sample. Moreover, the decline in likelihood of parttime work is slower, which slows down the recovery of the likelihood of full-time employment. The Dynamic Model predicts that a combination of these factors lead a temporary disability having a small (around 1 percent) but permanent effect on the probability of finding a full-time employment for this group.

The impact of a one-time disability shock is much more dramatic for the low-skilled female sample. Recovery of the likelihood of full-time work is slow and is not fully realised even 6 years after the shock. Two main factors may contribute to this pattern. First, initially, the impact on the likelihood of employment is much larger than the other sub-samples. Although the likelihood of full-time employment declines at a rate comparable to those of high-skilled women, the overall impact on employment is much larger due to the drop in likelihood of part-time work (which actually rises for high-skilled women). As a result, the likelihood of full-time work is lower by about 2 percent than its pre-shock levels even at $t=8$. 


\section{CONCLUSION}

In this paper the impact of work limiting disabilities on multi-state employment choices are investigated using dynamic models that allow for state dependence, unobserved heterogeneity and interaction between lagged employment states and work disability.

The impact of work disability on full time employment is found to be highly significant and economically large. Current disability is associated with a reduction of around 11.5 and 8.4 percent in the likelihood of full-time work for men and women, respectively. Moreover, due to high own state dependence the full effect on employment may be even higher. For example, since a part time worker is more likely to continue part time work than to transit into full time employment, switching to a part time job to accommodate a temporary disability may have prolonged adverse affects on the likelihood of full time employment.

Model simulations are presented to capture the intertemporal effect of disability for men and women with different skill levels. For low-skilled men and women the simulated probability of full-time employment is altered permanently due to a disability that last only one period. Lowskilled individuals that exit full-time employment either to enter part-time employment or to leave the labour force have big difficulties to re-enter full time employment. Even for highskilled people, the impact of a disability is expected to be long lasting. For example, the likelihood of full-time employment for high-skilled women who experience a temporary disability returns back to pre-shock levels only 6 years after the shock. There might be two factors driving this outcome. First, like men, high persistence of employment behaviour slows down the recovery; second, because part-time work is also strongly state dependent for women, those who switch from full time work to part time work tend to stay there longer. Moreover, women who initially leave the labour force due to a disability do not promptly return to full time 
work but may settle for part time employment instead.

The magnitude of the cross lagged state parameters suggest that an unemployed individual is far more likely to switch to full time employment than a part-time worker. However this difference disappears for the disabled. The estimated initial impact of disability on part-time work is approximately 2 percent increase for men and a 1.6 percent decrease for women. However, these modest outcomes mask significant cross-state movements. For example, a small decline in part-time female employment hides a large inflow of disabled full-time workers and disabled unemployed individuals into part-time employment.

This paper gives a dynamic disaggregated analysis of the interaction between disability and employment choices. I find significant discrepancies among how full time, part time and unemployment propensities react to a disability shock. Results suggest that policies that solely aim to build incentives for labour force participation may have mixed results if they ignore the source of this heterogeneity. 


\section{Table 1: Mean of the Demographic Characteristics}

\begin{tabular}{llcc}
\hline Variables & Definition & MEN & WOMEN \\
\hline FT & 1 if employed full time & 0.76 & 0.39 \\
PT & 1 if employed part time & 0.09 & 0.34 \\
UNEMP & 1 if unemployed & 0.02 & 0.02 \\
NILF & 1 if not in the labour force & 0.13 & 0.25 \\
WORKLIM & 1 if work limited & 0.16 & 0.15 \\
AGE & (Age - 24)/10 & 2.04 & 1.83 \\
AGE2 & AGE SQUARED /10 & 0.53 & 0.42 \\
AUST & 1 if Australian born & 0.76 & 0.76 \\
MCITY & 1 if resides in a major city & 0.61 & 0.61 \\
BAPLUS & 1 if completed Bachelor degree or higher & 0.25 & 0.28 \\
MAR & 1 if married or in a de facto relationship & 0.77 & 0.75 \\
KID014 & 1 if has child(ren) btw 0-14 years old & 0.37 & 0.46 \\
MARxKID014 & 1 if married and has child(ren) btw 0-14 years old & 0.36 & 0.38 \\
WTCOL1 & 1 if current/last occupation manager, admin., & 0.39 & 0.35 \\
& professional & & \\
WTCOL2 & 1 if current/last occupation clerical, sales or & 0.18 & 0.48 \\
& service worker & & \\
BLCOL & 1 if current/last occupation tradesperson, & 0.43 & 0.17 \\
UNEMPHST & \% time spent unemployed after education & & \\
WORKEXP & \% time spent employed after education & 0.05 & 0.04 \\
TABLE 1 cont. & & 0.91 & 0.73 \\
LOTHINC & Logarithm of Household non-labour income & & \\
PRTINLF & 1 if partner in the labour force & 0.83 & 0.89 \\
Observations & & 0.53 & 0.63 \\
\hline
\end{tabular}

Note: Above figures are generated using pooled sample of 7 waves of HILDA

Table 2: Employment Characteristics by Work Limitation

\begin{tabular}{lccccc}
\hline \hline & & Full Time & Part time & Unemployed & NILF \\
\hline Not Limited & MEN & & & & \\
Limited & & 0.84 & 0.08 & 0.02 & 0.06 \\
& WOMEN & 0.34 & 0.13 & 0.04 & 0.48 \\
Not Limited & & 0.42 & 0.36 & 0.02 & 0.21 \\
Limited & & 0.21 & 0.25 & 0.04 & 0.49 \\
\hline \hline
\end{tabular}

Note: See Table 1 
Figure 1: Probability of Switching to Full time Employment Conditional on Initial Employment State and Disability
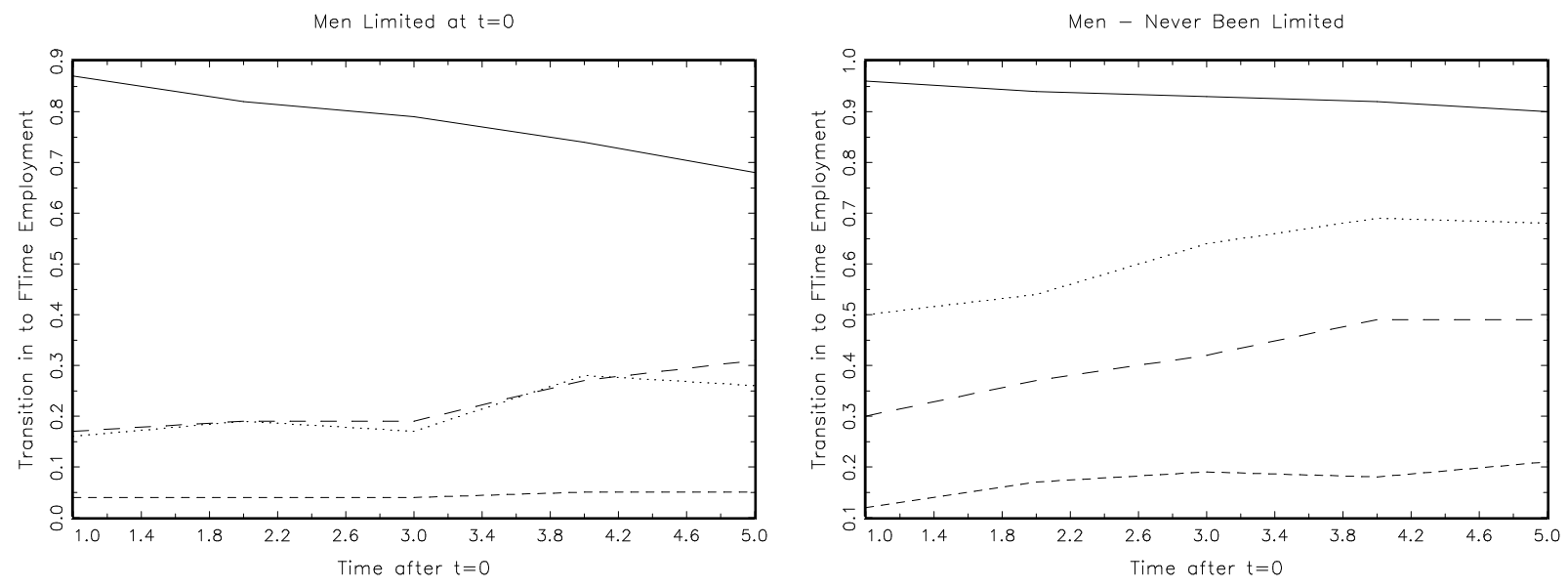

WoMen - Limited at $t=0$

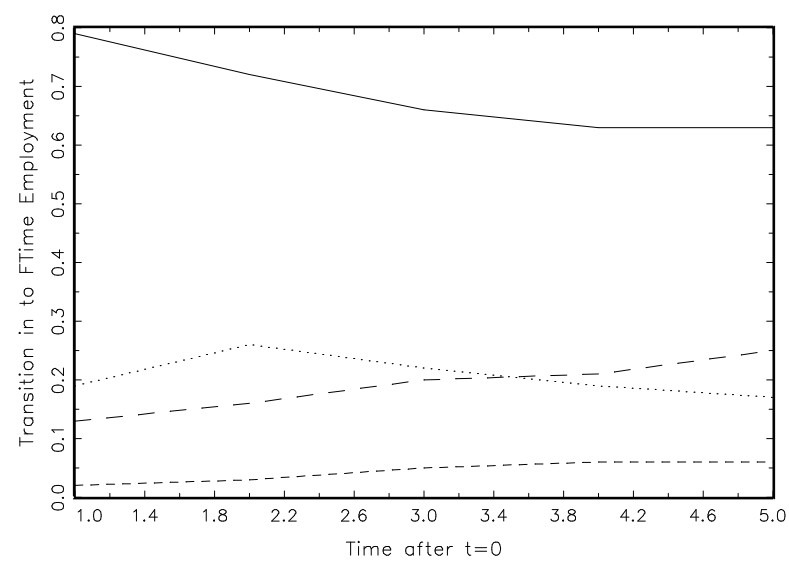

WoMen - Never Been Limited

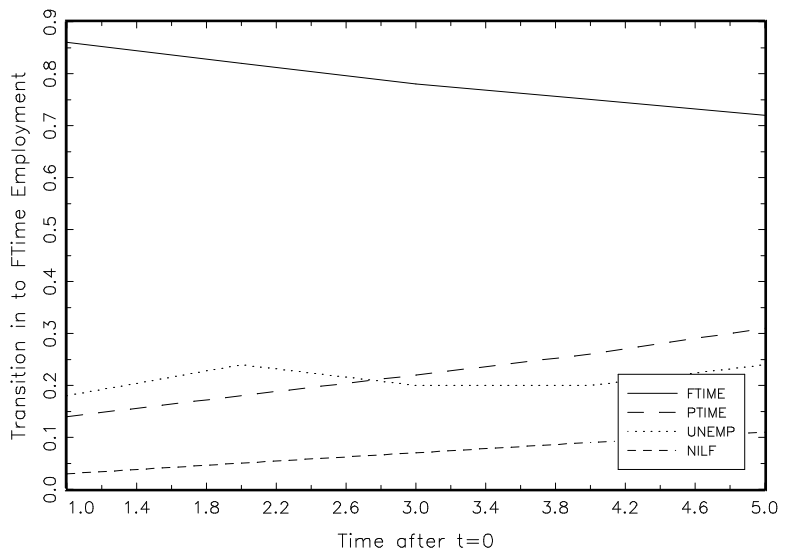

Note: FTIME,PTIME, UNEMP and NILF refer to full time employed, part time employed, unemployed, and not in the labour force at $\mathrm{t}=1$ respectively. 
Figure 2: Probability of Switching into Part time Employment Conditional on Initial Employment State and Disability
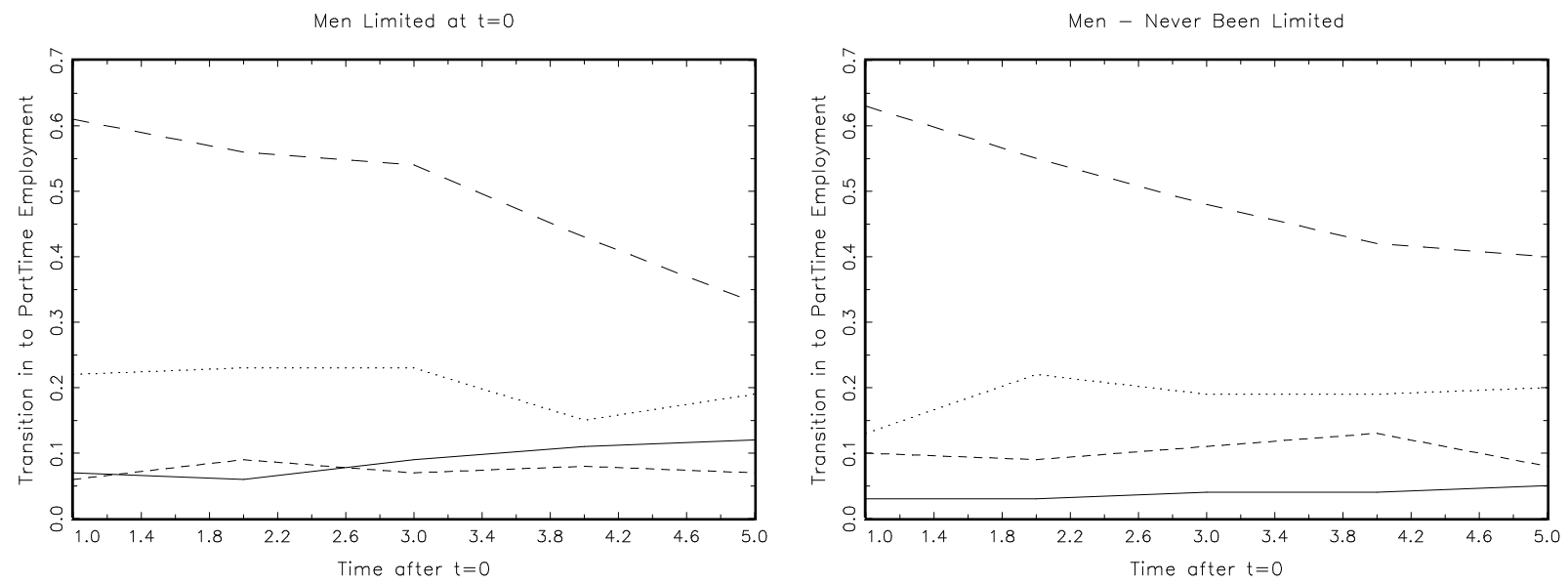

Women - Limited at $t=0$

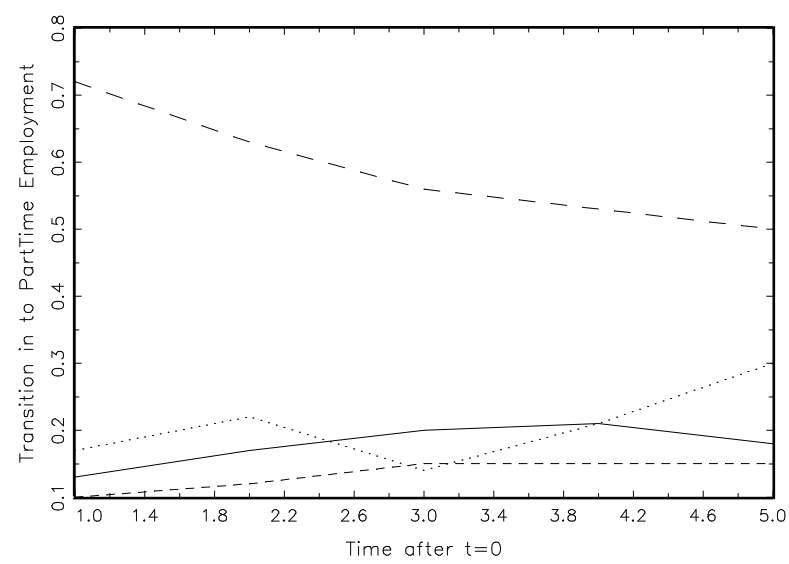

WoMen - Never Been Limited

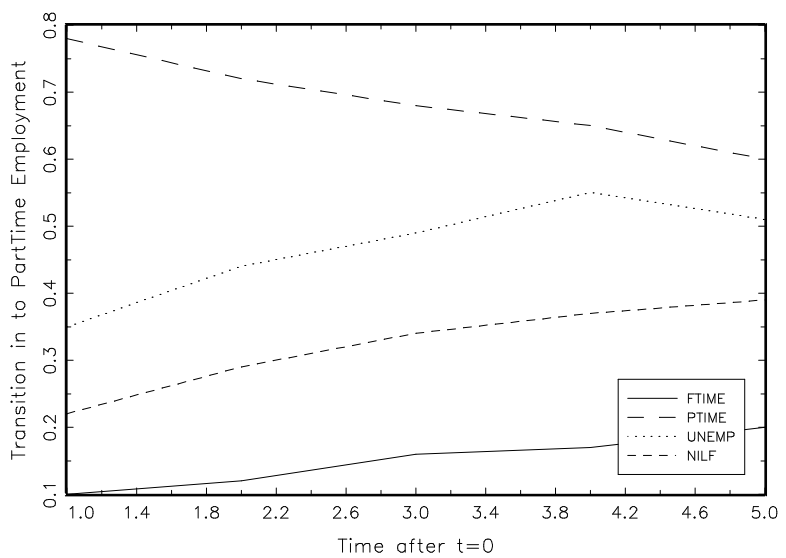

Note: FTIME,PTIME, UNEMP and NILF refer to full time employed, part time employed, unemployed, and not in the labour force at $\mathrm{t}=1$ respectively. 
TABLE 3 - DYNAMIC MIXED MULTINOMIAL RESULTS - MEN

\begin{tabular}{|c|c|c|c|c|c|c|}
\hline \multirow[t]{2}{*}{ MEN } & \multicolumn{2}{|c|}{ UNEMP } & \multicolumn{2}{|c|}{ PART TIME } & \multicolumn{2}{|c|}{ FULL TIME } \\
\hline & Coef. & S.E & Coef. & S.E & Coef. & S.E \\
\hline LFT & $1.61611^{* * *}$ & 0.20 & $1.89271^{* * * *}$ & 0.13 & $4.62164^{* * *}$ & 0.12 \\
\hline LPT & $1.22040^{* * *}$ & 0.22 & $3.25665^{\text {*** }}$ & 0.12 & $2.49790^{* * *}$ & 0.15 \\
\hline LUNEMP & $2.13513^{* * *}$ & 0.19 & $1.52147^{* * *}$ & 0.19 & $2.22941^{* * *}$ & 0.19 \\
\hline LWORKLIM & $-.60328^{* * *}$ & 0.18 & -0.06579 & 0.13 & $-.20718^{*}$ & 0.12 \\
\hline WORKLIM & $-.72449^{* * *}$ & 0.16 & $-.96192^{* * *}$ & 0.13 & $-1.91749^{* * *}$ & 0.11 \\
\hline AGE & -1.52362 & 1.02 & $-1.28551^{*}$ & 0.78 & 0.08565 & 0.72 \\
\hline AGE2 & $-2.70810^{* * * *}$ & 0.63 & $-.86479^{*}$ & 0.45 & $-3.67681^{* * *}$ & 0.42 \\
\hline AUST & -0.24075 & 0.15 & -0.06117 & 0.11 & -0.06969 & 0.10 \\
\hline MCITY & 0.14419 & 0.14 & -0.06217 & 0.10 & 0.12934 & 0.09 \\
\hline BACHPLUS & 0.30392 & 0.22 & $.71432^{* * *}$ & 0.14 & $.53244^{* * *}$ & 0.13 \\
\hline UNEMPHST & $1.97022^{* *}$ & 0.96 & 0.19754 & 0.92 & 0.2577 & 0.74 \\
\hline WORKEXP & -1.49121 & 2.02 & 2.93342 & 2.17 & $3.38730^{*}$ & 1.73 \\
\hline WTCOL2 & 0.12613 & 0.22 & $.23919^{*}$ & 0.14 & -0.10208 & 0.13 \\
\hline BLCOL & $.47717^{* *}$ & 0.19 & $.31538^{* * *}$ & 0.11 & 0.02396 & 0.11 \\
\hline MAR & 0.4223 & 0.47 & $-.90054^{* *}$ & 0.39 & -0.15577 & 0.34 \\
\hline KID014 & $-1.00225^{*}$ & 0.53 & -0.26417 & 0.48 & $-1.27733^{* * *}$ & 0.45 \\
\hline MARxKID014 & 0.34088 & 0.45 & 0.19417 & 0.40 & $.75111^{*}$ & 0.39 \\
\hline LOTHINC & -0.43417 & 0.33 & 0.0834 & 0.27 & -0.34773 & 0.23 \\
\hline PRTINLF & 0.28487 & 0.29 & $.80243^{* * *}$ & 0.17 & $1.04955^{* * *}$ & 0.16 \\
\hline$\alpha_{j}$ & $-2.61204^{* * *}$ & .53 & $\bar{z}^{-} .82194^{* * *}$ & .38 & $-3.91756^{* * *}$ & .34 \\
\hline$\sigma_{j}$ & 0.084 & .067 & $.76038^{* * *}$ & .04 & $.61258^{* * * *}$ & .03 \\
\hline$\sigma_{f t, p t}=0.38$ & $48, \sigma_{p t, u n e}$ & & & & & \\
\hline
\end{tabular}

Note: All models include time averages of all time varying control variables and time dummies $*$ $p<0.10, * * p<0.05, * * * p<0.01$ 
TABLE 4 - DYNAMIC MIXED MULTINOMIAL RESULTS - WOMEN

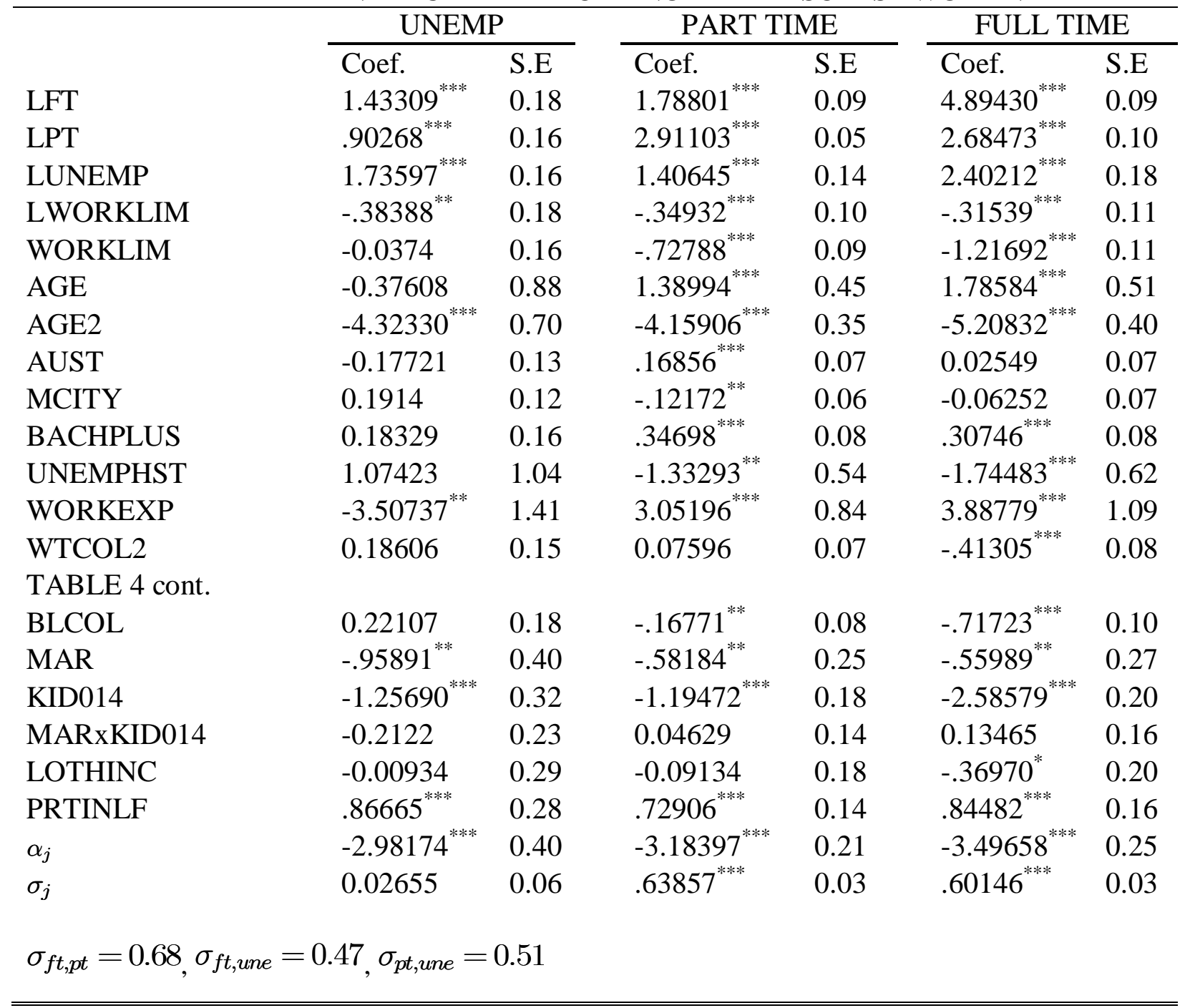

Note: See Table 3 
TABLE 5 - DYNAMIC MIXED MULTINOMIAL RESULTS - INTERACTION MODEL

\begin{tabular}{|c|c|c|c|c|c|c|}
\hline \multirow[t]{2}{*}{$\underline{\text { MEN }}$} & \multicolumn{2}{|c|}{ UNEMP } & \multicolumn{2}{|c|}{ PART TIME } & \multicolumn{2}{|c|}{ FULL TIME } \\
\hline & Coef. & S.E & Coef. & S.E & Coef. & S.E \\
\hline LFT & $1.66196^{* * * *}$ & 0.23 & $1.66224^{* * *}$ & 0.09 & $4.75973^{* * *}$ & 0.10 \\
\hline LPT & $1.17758^{* * *}$ & 0.29 & $2.90264^{* * * *}$ & 0.06 & $2.68935^{* * *}$ & 0.11 \\
\hline LUNEMP & $2.29792^{* * * *}$ & 0.26 & $1.27192^{* * *}$ & 0.16 & $2.31535^{* * *}$ & 0.20 \\
\hline \multicolumn{7}{|l|}{ WORKLIM } \\
\hline x LFT & $-.90415^{* * *}$ & 0.27 & $-.37136^{*}$ & 0.20 & $-.91656^{* * *}$ & 0.17 \\
\hline x LPT & -0.53573 & 0.39 & $-.80630^{* * * *}$ & 0.13 & $-1.35855^{* * *}$ & 0.18 \\
\hline x LUNE & $-.84955^{* * *}$ & 0.30 & -0.47543 & 0.29 & $-1.36970^{* * *}$ & 0.39 \\
\hline x LNILF & $-.70571^{* * *}$ & 0.26 & $-.88982^{* * *}$ & 0.13 & $-1.25099^{* * *}$ & 0.23 \\
\hline LWORKLIM & $-.62646^{* * *}$ & 0.18 & $-.35225^{* * *}$ & 0.10 & $-.33231^{* * * *}$ & 0.11 \\
\hline WOMEN & \multicolumn{2}{|c|}{ UNEMP } & \multicolumn{2}{|c|}{ " PART TIME } & \multicolumn{2}{|c|}{ "FULL TIME } \\
\hline LFT & $1.17777^{* * *}$ & 0.20 & $1.66224^{k * * *}$ & 0.09 & $4.75973^{* * *}$ & 0.10 \\
\hline LPT & $.83243^{* * *}$ & 0.17 & $2.90264^{* * *}$ & 0.06 & $2.68935^{* * *}$ & 0.11 \\
\hline LUNEMP & $1.73769^{\text {*** }}$ & 0.18 & $1.27192^{* * *}$ & 0.16 & $2.31535^{* * *}$ & 0.20 \\
\hline \multicolumn{7}{|l|}{ WORKLIM } \\
\hline x LFT & 0.43783 & 0.33 & $-.37136^{*}$ & 0.20 & $-.91656^{* * *}$ & 0.17 \\
\hline$x$ LPT & -0.19993 & 0.33 & $-.80630^{* * *}$ & 0.13 & $-1.35855^{* * *}$ & 0.18 \\
\hline x LUNE & -0.07049 & 0.34 & -0.47543 & 0.29 & $-1.36970^{* * *}$ & 0.39 \\
\hline x LNILF & -0.11331 & 0.20 & $-.88982^{* * * *}$ & 0.13 & $-1.25099^{* * *}$ & 0.23 \\
\hline LWORKLIM & $-.40116^{* *}$ & 0.18 & $-.35225^{* * *}$ & 0.10 & $-.33231^{* * * *}$ & 0.11 \\
\hline
\end{tabular}

Note: Model include all control variables used in the Dynamic Models. 
TABLE 6: AVERAGE PARTIAL EFFECTS

\begin{tabular}{|c|c|c|c|c|c|c|c|c|}
\hline & \multicolumn{4}{|c|}{ MEN } & \multicolumn{4}{|c|}{ WOMEN } \\
\hline & \multicolumn{4}{|c|}{ State at $t$} & \multicolumn{4}{|c|}{ State at $t$} \\
\hline & NILF & UNEMP & PT & FT & NILF & UNEMP & PT & FT \\
\hline \multicolumn{9}{|c|}{ Dynamic Model } \\
\hline LFT & -37.67 & -3.83 & -8.98 & 50.49 & -50.55 & -1.34 & -13.21 & 65.10 \\
\hline LPT & -34.12 & -2.77 & 28.47 & 8.42 & -47.38 & -1.58 & 41.62 & 7.35 \\
\hline LUNE & -27.55 & 4.76 & 0.20 & 22.59 & -33.85 & 3.62 & 9.76 & 20.48 \\
\hline LWORKLIM & 0.90 & -0.80 & 0.55 & -0.66 & 3.54 & -0.37 & -2.54 & -0.63 \\
\hline WORKLIM & 8.26 & 1.07 & 2.17 & -11.50 & 9.03 & 1.03 & -1.67 & -8.39 \\
\hline \multicolumn{9}{|c|}{ Dynamic Interaction Model } \\
\hline LFT & -42.52 & -4.48 & -10.28 & 57.28 & -54.12 & -51.18 & -37.06 & 2.72 \\
\hline LPT & -38.38 & -3.52 & 30.57 & 11.33 & -1.48 & -1.49 & 3.41 & -0.33 \\
\hline LUNE & -33.55 & 3.82 & -0.78 & 30.50 & -12.88 & 43.13 & 9.37 & -1.94 \\
\hline LWORKLIM & 0.81 & -0.81 & 0.50 & -0.49 & 68.48 & 9.54 & 24.28 & -0.44 \\
\hline \multicolumn{9}{|l|}{ WORKLIM } \\
\hline $\mathrm{x}$ LFT & 9.03 & 1.19 & 2.88 & -13.10 & 5.54 & 2.35 & 4.79 & -12.68 \\
\hline$x$ LPT & 12.63 & 2.38 & 3.74 & -18.75 & 9.27 & 0.84 & -2.49 & -7.62 \\
\hline x LUNE & 21.28 & 6.99 & 7.47 & -35.75 & 10.25 & 3.38 & 3.09 & -16.72 \\
\hline x LNILF & 10.10 & 1.74 & 2.00 & -13.84 & 15.35 & 3.56 & -6.67 & -12.23 \\
\hline
\end{tabular}

Note: APEs are computed at the means of individuals' characteristics (i.e. $\overline{x_{i}}$ ) 
TABLE 7: Linear Probability Models - MEN

\begin{tabular}{|c|c|c|c|c|c|c|}
\hline \multirow{2}{*}{$\begin{array}{l}\text { Model: } \\
\text { LFT }\end{array}$} & \multicolumn{2}{|c|}{ Full time Work } & \multicolumn{2}{|c|}{ Part time Work } & \multicolumn{2}{|c|}{ Unemployment } \\
\hline & $0.339^{* * * *}$ & $0.432^{\text {**** }}$ & -0.002 & -0.012 & $-0.067^{* * *}$ & $-0.074^{* * *}$ \\
\hline & $(0.033)$ & $(0.049)$ & $(0.035)$ & $(0.052)$ & $(0.020)$ & $(0.029)$ \\
\hline \multirow[t]{2}{*}{ LPT } & $0.0921^{* * *}$ & $0.140^{* * * *}$ & $0.197^{* * *}$ & $0.247^{* * *}$ & $-0.054^{* * * *}$ & $-0.072^{* * * *}$ \\
\hline & $(0.031)$ & $(0.042)$ & $(0.034)$ & $(0.047)$ & $(0.020)$ & $(0.025)$ \\
\hline \multirow[t]{2}{*}{ LUNE } & $0.115^{* * * *}$ & $0.131^{* * *}$ & 0.033 & 0.042 & $0.058^{*}$ & 0.050 \\
\hline & $(0.034)$ & $(0.053)$ & $(0.039)$ & $(0.060)$ & $(0.032)$ & $(0.043)$ \\
\hline \multirow[t]{2}{*}{ WORKLIM } & $-0.093^{* * *}$ & $-0.092^{* * *}$ & -0.016 & 0.005 & 0.016 & 0.010 \\
\hline & $(0.021)$ & $(0.023)$ & $(0.021)$ & $(0.022)$ & $(0.013)$ & $(0.013)$ \\
\hline \multirow[t]{2}{*}{ LWORKLIM } & $<0.001$ & -0.001 & $-0.027^{*}$ & -0.016 & $<0.001$ & 0.002 \\
\hline & $(0.015)$ & $(0.016)$ & $(0.015)$ & $(0.016)$ & $(0.010)$ & $(0.010)$ \\
\hline \multirow[t]{2}{*}{ LLFT } & & $0.111^{* * *}$ & & -0.045 & & -0.037 \\
\hline & & $(0.034)$ & & $(0.040)$ & & $(0.024)$ \\
\hline \multirow[t]{2}{*}{ LLPT } & & $0.067^{*}$ & & 0.025 & & -0.034 \\
\hline & & $(0.037)$ & & $(0.043)$ & & $(0.024)$ \\
\hline \multirow[t]{2}{*}{ LLUNE } & & 0.032 & & -0.007 & & -0.024 \\
\hline & & $(0.036)$ & & $(0.041)$ & & $(0.031)$ \\
\hline \# Instruments & 55 & 50 & 55 & 50 & 55 & 50 \\
\hline Sargan Test & $22.82[0.85]$ & $27.54[0.27]$ & $19.06[0.95]$ & $18.52[0.77]$ & $28.35[0.60]$ & $14.73[0.92]$ \\
\hline $\mathrm{AR}(2)$ & $2.82[0.004]$ & $1.07[0.28]$ & $1.100[0.27]$ & $0.07[0.93]$ & $0.738[0.46]$ & $0.29[0.76]$ \\
\hline $\mathrm{AR}(3)$ & $0.456[0.648]$ & $-0.42[0.66]$ & $1.45[0.14]$ & $0.26[0.79]$ & $-0.85[0.39]$ & $-0.48[0.62]$ \\
\hline
\end{tabular}

Note: Models include all time varying variables used in the multinomial models. Standard errors in parentheses. P-values for Sargan Test and $\mathrm{AR}(\mathrm{p})$ tests are in brackets.* $p<0.10, * * p<0.05$, *** $p<0.01$. Null hypothesis of Sargan test is instruments are valid. The null hypothesis for $\mathrm{AR}(\mathrm{p})$ test is no serial correlation of order $\mathrm{p}$. 
TABLE 8: Linear Probability Models - WOMEN

\begin{tabular}{lcccccc}
\hline Model: & \multicolumn{2}{c}{ Full time Work } & \multicolumn{2}{c}{ Part time Work } & \multicolumn{2}{c}{ Unemployment } \\
\hline LFT & $0.297^{* * *}$ & $0.465^{* * *}$ & -0.001 & $-0.101^{* *}$ & 0.014 & -0.015 \\
& $(0.030)$ & $(0.038)$ & $(0.039)$ & $(0.053)$ & $(0.015)$ & $(0.020)$ \\
LPT & 0.007 & 0.052 & $0.263^{* * *}$ & $0.302^{* * *}$ & 0.006 & -0.029 \\
& $(0.021)$ & $(0.033)$ & $(0.032)$ & $(0.050)$ & $(0.013)$ & $(0.020)$ \\
LUNE & 0.035 & $0.111^{* * *}$ & $0.073^{*}$ & 0.105 & $0.083^{* * *}$ & $0.075^{* *}$ \\
& $(0.029)$ & $(0.041)$ & $(0.038)$ & $(0.064)$ & $(0.027)$ & $(0.034)$ \\
WORKLIM & $-0.044^{* *}$ & $-0.061^{* *}$ & $-0.049^{*}$ & $-0.067^{* *}$ & 0.013 & 0.004 \\
& $(0.020)$ & $(0.024)$ & $(0.026)$ & $(0.032)$ & $(0.011)$ & $(0.013)$ \\
LWORKLIM & $<0.001$ & 0.007 & $-0.036^{*}$ & $-0.050^{* *}$ & 0.002 & -0.001 \\
& $(0.015$ & $(0.018)$ & $(0.019)$ & $(0.022)$ & $(0.008)$ & $(0.010)$ \\
LLFT & & $0.155^{* * *}$ & & -0.046 & & -0.008 \\
& & $(0.027)$ & & $(0.034)$ & & $(0.012)$ \\
LLPT & & 0.023 & & $0.069^{* * *}$ & & -0.010 \\
& & $(0.019)$ & & $(0.028)$ & & $(0.012)$ \\
LLUNE & & $0.056^{*}$ & & 0.0048 & & 0.040 \\
& & $(0.031)$ & & $(0.040)$ & & $(0.027)$ \\
\hline \# Instruments & 55 & 50 & 55 & 50 & 55 & 50 \\
Sargan & $27.36[0.65]$ & $28.73[0.23]$ & $18.44[0.96]$ & $19.09[0.74]$ & $34.51[0.30]$ & $22.01[0.57]$ \\
AR(2) & $3.48[0.00]$ & $-0.85[0.39]$ & $4.12[0.00]$ & $1.40[0.16]$ & $0.19[0.84]$ & $-1.81[0.07]$ \\
AR(3) & $-0.36[0.71]$ & $0.94[0.34]$ & $-1.22[0.21]$ & $-0.64[0.52]$ & $0.007[0.99]$ & $0.80[0.42]$ \\
\hline Note: See Tan & 8 & & & & &
\end{tabular}

Note: See Table 8 
FIGURE 3: Employment Response after Disability -High Skilled Persons

MEN EMPLOYMENT RESPONSE AFTER DISABILITY High Skilled

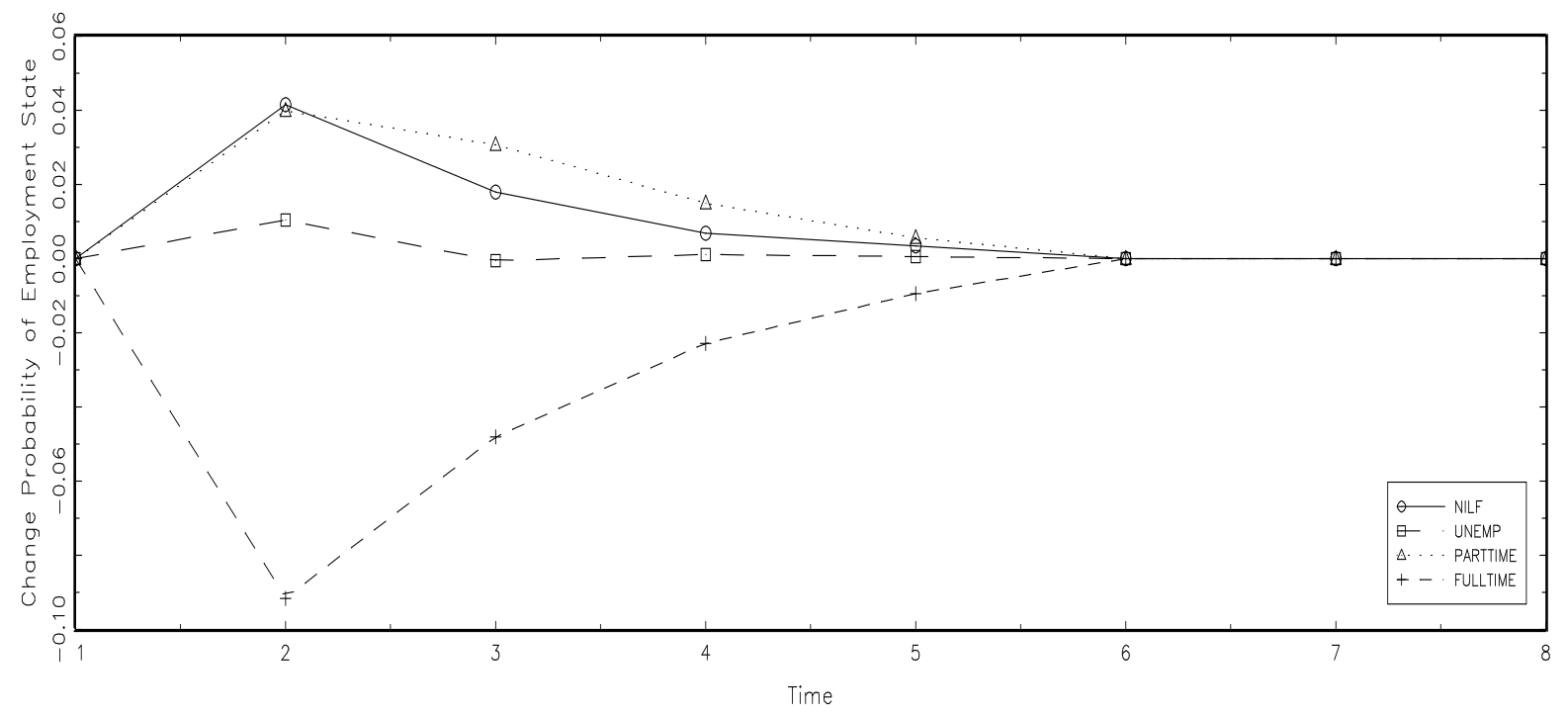

WOMEN EMPLOYMENT RESPONSE AFTER DISABILITY High Skilled

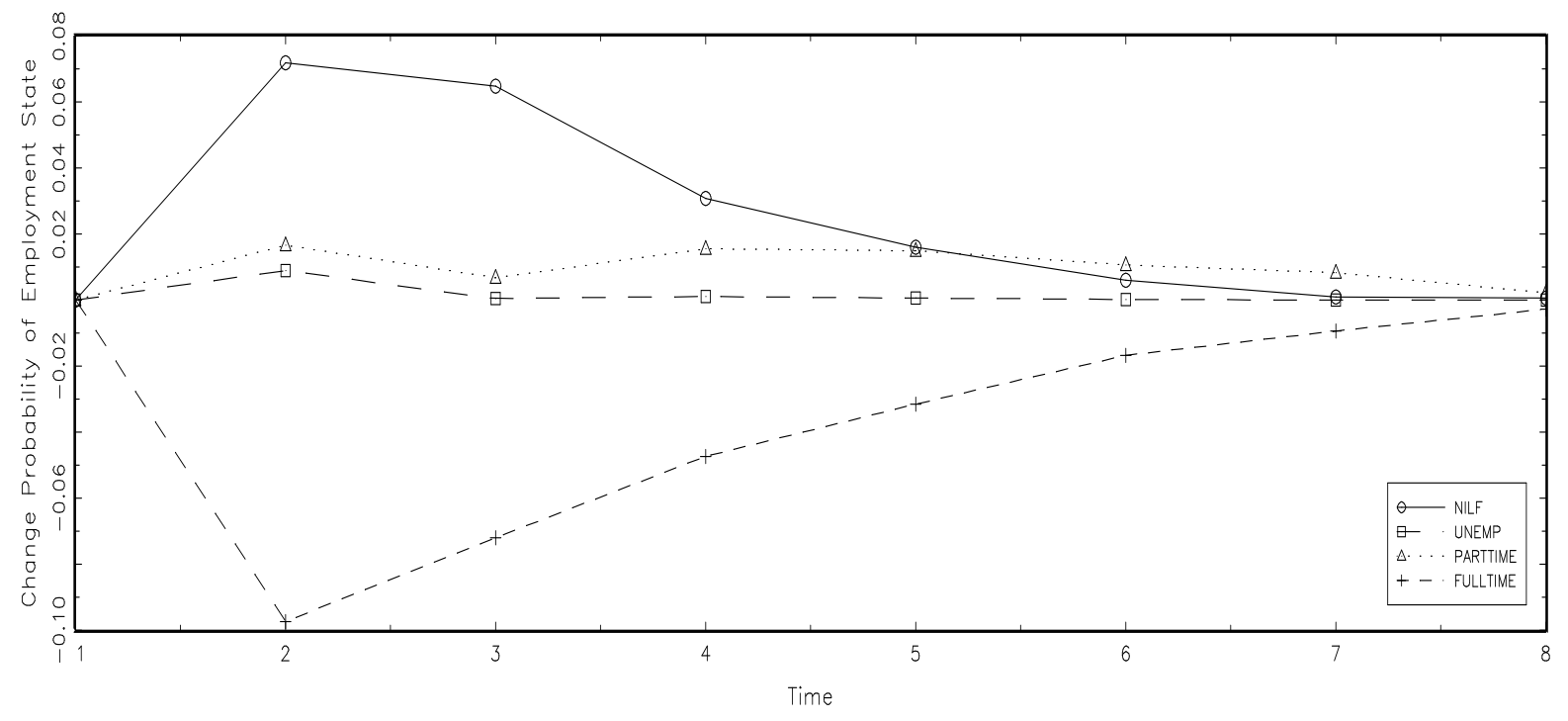


FIGURE 4: Employment Response after Disability -Low Skilled Persons

MEN EMPLOYMENT RESPONSE AFTER DISABILITY LOW Skilled

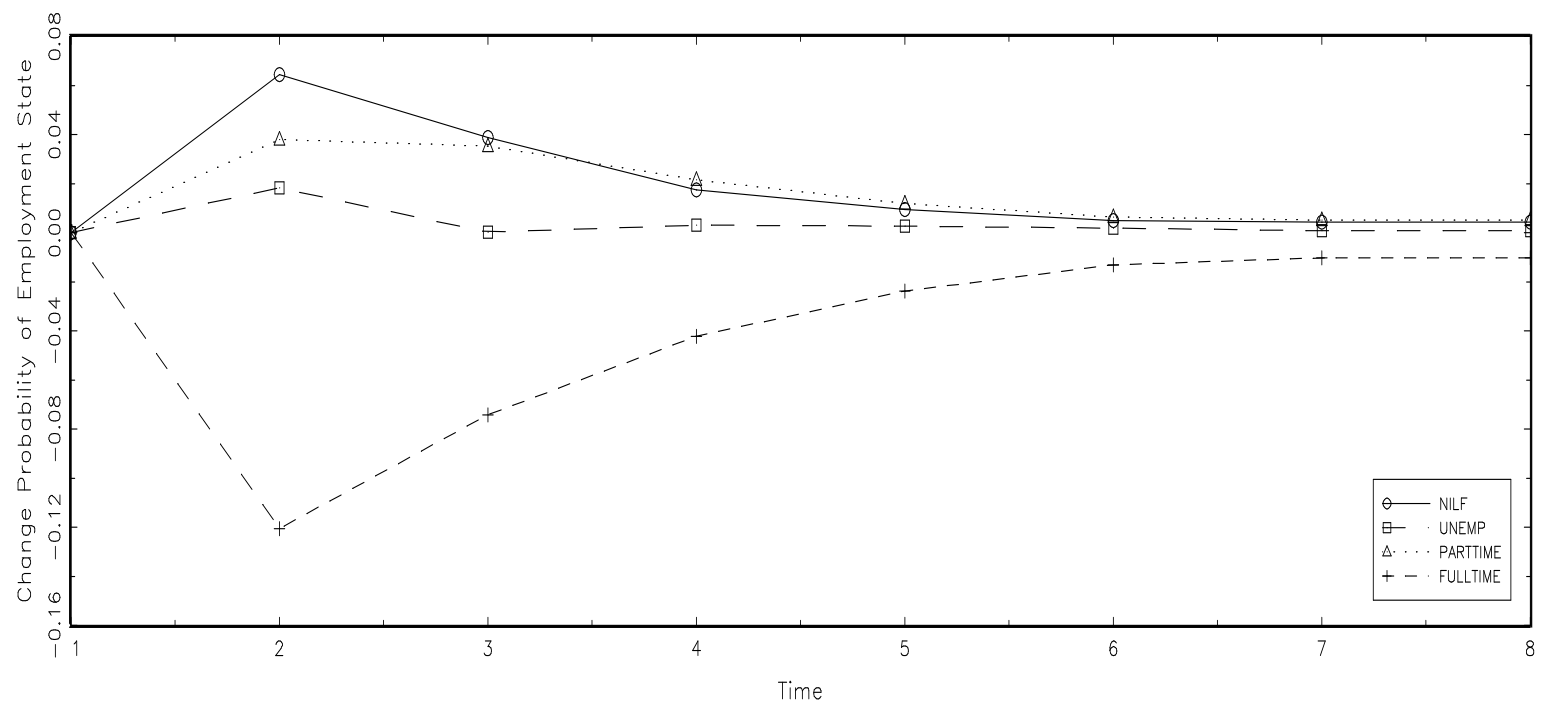

WOMEN EMPLOYMENT RESPONSE AFTER DISABILITY LOW Skilled

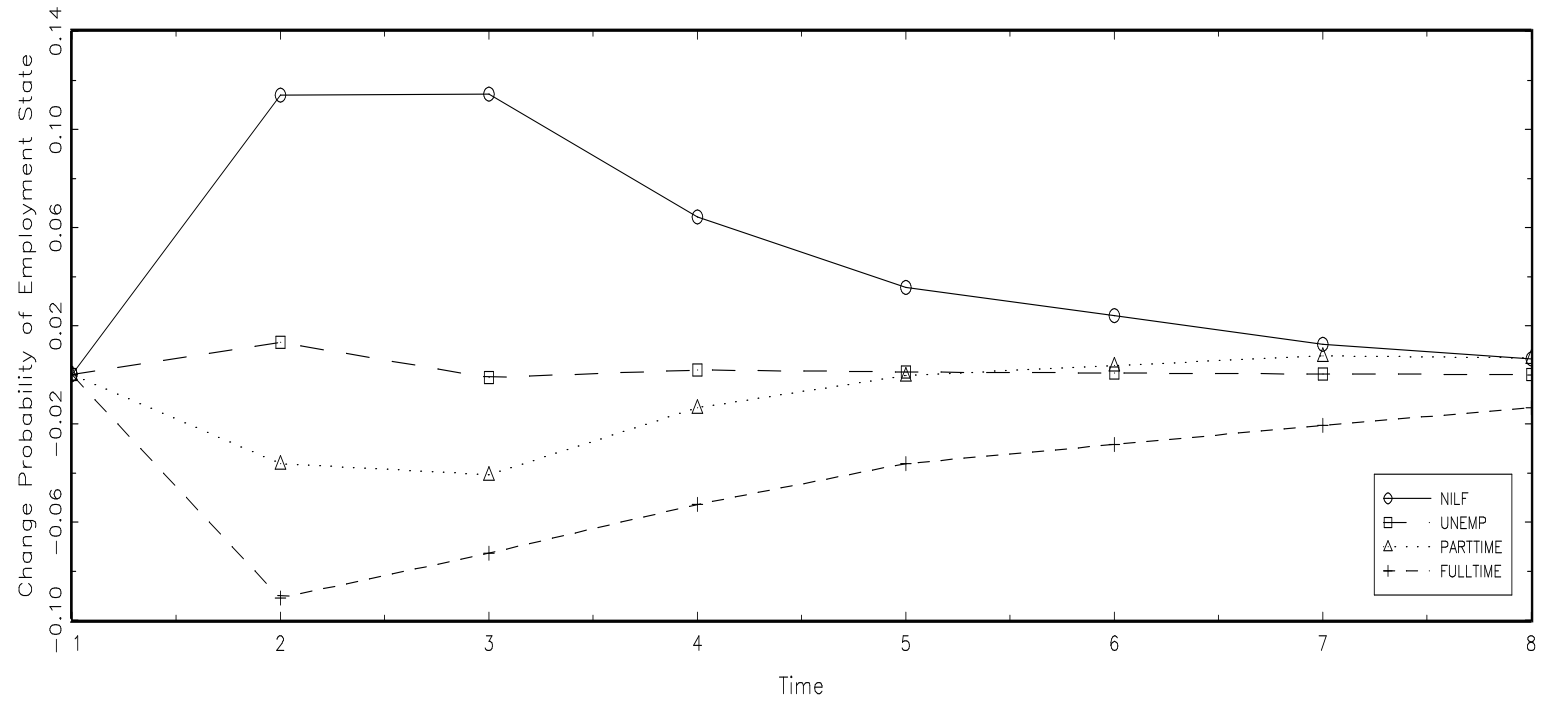




\section{REFERENCES}

Arellano, M, \& Bover, O. (1995). Another look at the instrumental variable estimation of errorcomponents models. Journal of econometrics, 68(1), 29-52. [Amsterdam: North-Holland Pub. Co.], 1973-.

Arellano, M., \& Bond, S. (1991). Some tests of specification for panel data: Monte Carlo evidence and an application to employment equations. The Review of Economic Studies, 58(2), 277-297.

Arulampalam, W., Gregg, P., \& Gregory, M. (2001). Unemployment Scarring. The Economic Journal, 111(475), 626-653. doi: 10.1111/1468-0297.00666.

Blank, R. (1989). The Role of Part-Time Work in Women's Labor Market Choices over Time. The American Economic Review, 79(2), 295-299.

Bound, J. (1991). Self-Reported Versus Objective Measures of Health in Retirement Models. Journal of Human Resources, 26(1), 106-138.

Burkhauser, R. V., \& Daly, M. C. (1994). The Economic Consequences of Disability: A Comparison of German and American People With Disabilities. Journal of Disability Policy Studies, 5(1), 25-52. doi: 10.1177/104420739400500102.

Cai, L. (2010). The relationship between health and labour force participation : Evidence from a panel data simultaneous equation model. Labour Economics, 17(1), 77-90. Elsevier B.V.

Campolieti, M. (2002). Disability and the labor force participation of older men in Canada. Labour Economics, 9(3), 405-432.

Charles, K. (2003). The Longitudinal Structure of Earnings Losses among Work-Limited Disabled Workers. The Journal of Human Resources, 38(3), 618. doi: 10.2307/1558770.

Farber, H. S. (1999). Alternative and Part- Time Employment Arrangements as a Response to Job Loss. Journal of Labor Economics, 17(s4), S142-S169. doi: 10.1086/209946.

Gannon, B. (2005). A dynamic analysis of disability and labour force participation in Ireland1995 - 2000. Health Economics, 14(October 2004), 925-938. doi: 10.1002/hec.1044.

Geweke, J. (1988). Antithetic acceleration of Monte Carlo integration in Bayesian inference. Journal of Econometrics, 38(1-2), 73-89. Elsevier.

Gong, X., Van Soest, A., \& Villagomez, E. (2004). Mobility in the Urban Labor Market : A Panel Data Analysis for Mexico. Economic Development and Cultural Change, 53(1), 1-36. 
Hajivassiliou, V. (1993). Simulation estimation methods for limited dependent variable models. In G. S. Maddala, C. R. Rao, \& H. D. Vinod (Eds.), Handbook of Statistics. (pp. 519-543). North-Holland, Amsterdam.

Heckman, J. J. (1981). The Incidental Parameters Problem and the Problem of Initial Conditions in Estimating a Discrete Time-Discrete Data Stochastic Process and Some Monte Carlo Evidence. Structural Analysis of Discrete Data with Econometric Applications. London : MIT Press.

Kapteyn, A., Smith, J. P., \& Soest, A. van. (2008). Dynamics of work disability and pain. Journal of Health Economics, 27(2), 496-509. Elsevier.

Keane, M. P. (1994). A computationally practical simulation estimator for panel data. Econometrica: Journal of the Econometric Society, 62(1), 95-116. JSTOR.

LaRue, A., Bank, L., Jarvik, U., \& Hetland, M. (1979). Health in old age: How do physicians' ratings and self-ratings compare?. Journal of Gerontology.

Maddox, G., \& Douglas, E. (1973). Self-Assessment of Health: A Longitudinal Study of Elderly Subject. Journal of Health and Social Behaviour, 14, 87-93.

Mok, W. K. C., Meyer, B. D., Charles, K. K., \& Achen, A. C. (2010). Journal of Human Resources. Journal of Human Resources, (forthcomi.

Mundlak, Y. (1978). On the Pooling of Time Series and Cross Section Data. Econometrica, 46(1), 69-85.

Nagi, S. (1969). Congruency in Medical and Self-Assessment of Disability. Industrial Medicine, 27-36.

OECD. (2010). OECD Employment Outlook: Moving Beyond the Job Crisis.

Oguzoglu, U. (2010). Dynamics of Work Limitation and Work in Australia. Health Economics, $19(6), 656-669$.

Prowse, V. (2010). Modeling Employment Dynamics with State Dependence and Unobserved Heterogeneity. IZA Discussion Paper.

Ruhm, C. J. (2010). Are Workers Permanently Scarred by Job Displacements ?. The American Review Economic, 81(1), 319-324.

Stern, S. (1989). Measuring the Effect of Disability on Labor Force Participation. Journal of Human Resources, 24(3), 361-395.

Train, K. (2009). Discrete choice methods with simulation. Cambridge University Press. 
Ware, J. E. (2000). SF-36 Health Survey: Manual and interpretation guide. The Health Institute, New England Medical Center.

Watson, N., \& Wooden, M. (2004). HILDA Survey Four Years on. The Australian Economic Review, 37(3), 343-349. 